\title{
Erratum: "Josephson Effect in Thin Films: The Role of Vortex Excitations," Pis'ma Zh. Éksp. Teor. Fiz. 85, 74 (2007) [JETP Lett. 85, 67 (2007)]
}

\section{S. Khlebnikov}

Department of Physics, Purdue University, West Lafayette, Indiana, 47907 USA

e-mail: skhleb@physics.purdue.edu

Received September 7, 2007

PACS numbers: 74.50.+r, 74.78.Na

DOI: $10.1134 / \mathrm{S} 0021364007180166$

Equations (14) and (15) should have the form

$$
\begin{gathered}
F_{x}=-K_{s} \int d x d y \nabla \theta_{\Gamma} \frac{\partial}{\partial x_{0}} \nabla \theta_{1}=0, \\
F_{y}=0 .
\end{gathered}
$$

I offer my apology to the readers of the journal. 